\title{
Pharmacological and non-pharmacological treatment of adults with ADHD: a meta-review
}

\author{
Franco De Crescenzo, ${ }^{1}$ Samuele Cortese, ${ }^{2,3}$ Nicoletta Adamo, ${ }^{4}$ Luigi Janiri ${ }^{1}$
}

${ }^{1}$ Institute of Psychiatry and Psychology, Catholic University of Sacred Heart, Rome, Italy; ${ }^{2}$ Department of Psychology, Developmental Brain-Behaviour Laboratory, University of Southampton, and Solent NHS Trust, Southampton, UK; ${ }^{3}$ Langone Medical Center, New York University Child Study Center, New York City, New York, USA; ${ }^{4}$ MRC Social, Genetic and Developmental Psychiatry Centre, Institute of Psychiatry, Psychology \& Neuroscience, King's College London, London, UK

Correspondence to Dr Franco De Crescenzo, Institute of Psychiatry and Psychology, Catholic University of Sacred Heart, Largo A. Gemelli 8, Rome 00168, Italy; decrescenzo.franco@gmail.com

\section{ABSTRACT}

Attention-deficit/hyperactivity disorder (ADHD) is characterised by a persistent and impairing pattern of inattention and/or hyperactivity/impulsivity and it is one of the most common neuropsychiatric conditions. Evidence about interventions of adults with ADHD is growing rapidly and clinicians need a reliable summary of all the best available information in order to better inform their daily practice. We searched MEDLINE, PubMed, PsycINFO and Cochrane databases until 31 May 2016 for systematic reviews about pharmacological and non-pharmacological treatments in adults with ADHD and carried out a meta-review to address clinically relevant questions. We identified a total of 40 papers. Psychostimulants—such as methylphenidate, dexamphetamine, mixed amphetamine salts and lisdexamfetamine —and non-psychostimulants—such as atomoxetine—were the most studied agents. Overall, pharmacological treatments were significantly more efficacious than placebo (standardised mean difference (SMD) $0.45,95 \% \mathrm{Cl} 0.37$ to 0.52 ), albeit less well accepted (OR 1.18, 95\% Cl 1.02 to 1.36 ) and tolerated (OR 2.29, $95 \% \mathrm{Cl} 1.97$ to 2.66 ). The effects of pharmacological treatment for individuals with co-occurring ADHD and substance use disorder are still uncertain. The evidence for the efficacy and effectiveness of non-pharmacological treatments of ADHD in adults, as well as the combination of pharmacological and non-pharmacological strategies, is only preliminary. In conclusion, while available evidence addressed mainly the efficacy and tolerability of psychostimulants and nonpsychostimulants for ADHD core symptoms in the short term, we still need further empirical support for the non-pharmacological and multimodal treatments. A comprehensive evidence-informed hierarchy of ADHD drugs based on their efficacy and tolerability is not yet available but it should be the next research priority in the field.

\section{INTRODUCTION}

Attention-deficit/hyperactivity disorder (ADHD) is one of the most common neuropsychiatric conditions, ${ }^{1}$ with a pooled worldwide prevalence estimated at about $5 \%$ in school-aged children and persistence of impairing symptoms in adulthood in up to $65 \%$ of cases. ${ }^{1}$ The pooled estimated prevalence of ADHD (as categorical diagnosis) in adults is around $2.5 \%{ }^{1}$ $\mathrm{ADHD}$ is characterised by a persistent and impairing pattern of inattention and/or hyperactivity/impulsivity. According to the current edition of the Diagnostic and Statistical Manual of Mental Disorders (DSM-5), at least five out of nine symptoms of inattention and/or hyperactivity/ impulsivity are required for the diagnosis. Although, based on current diagnostic criteria, ADHD onset is by definition in childhood (more specifically, before the age of 12), recent research suggests that, in some cases, it might appear de novo in adulthood. ${ }^{2}$ Other diagnostic criteria require that symptoms are present in more than one setting (eg, academic, social and occupational) and lead to functional impairment in various domains. DSM- 5 defines three ADHD clinical presentations based on symptom profile: combined, predominantly inattentive and predominantly hyperactive/impulsive presentation. Changes from previous edition of the DSM (DSM-IV-TR) include, among others, the age of onset (now 'prior to age of 12', before 'prior to age of 7 '), the count threshold for the diagnosis in adults (at least five symptoms of inattention and/or hyperactivity/impulsivity, rather than six as in children) and the inclusion of specific age-appropriate examples of ADHD symptoms in adults. The International Classification of Diseases (ICD-10) describes a syndrome, namely, hyperkinetic disorder (HKD), which overlaps with the predominantly combined ADHD subtype in the DSM-IV. Specifically, the diagnosis of HKD requires symptoms of inattention and hyperactivity/impulsivity (table 1).

The assessment of an adult referred for possible ADHD includes the following: (1) identifying symptoms and behaviours consistent with DSM-5 diagnostic criteria for ADHD; (2) considering age of onset of symptoms; (3) estimating functional impairment; (4) evaluating pervasiveness of symptoms; (5) identifying coexisting disorders and (6) ruling out other psychiatric or somatic differential diagnoses. It is also important to record family history, to perform a physical and neurological examination and support the clinical judgement with questionnaires/rating scales. Guidelines from various countries agree on the importance of a clinical psychiatric interview in secondary care to confirm an ADHD diagnosis and start an appropriate treatment. ${ }^{3}$ The structured Diagnostic Interview for Adult ADHD (DIVA 2.0) based on DSM-IV criteria, can be of help to guide clinicians in the diagnosis. ${ }^{4}$

The diagnosis of ADHD in adulthood is relatively straightforward when symptoms are clearly present and the diagnosis was previously made in childhood. However, if not established during childhood, the diagnosis of ADHD in adults can be difficult. Particularly important is to interview at least one adult informant (such as a parent or a close relative), who can give information about the behaviour of the patient as a child. As most adults have a recall bias, it is difficult for them to recall the onset, severity and persistence of ADHD symptoms, and this makes it difficult to make a good assessment based only on the patients' own report. ${ }^{4}$ Having another informant in addition to the patient can also help to prevent patients from assuming a manipulative response style, which can lead to over or underestimation of symptoms or to obtain psychostimulants for non-medical use. ${ }^{1}$

Adult ADHD is often comorbid with other psychiatric disorders, such as depression, anxiety, substance use disorder, antisocial personality disorder and/or somatic conditions, such as obesity. ${ }^{4} \mathrm{~A}$ large body of evidence shows that untreated adult ADHD leads to negative psychosocial consequences, including poor education, antisocial acts, marital difficulties, incarceration and lower socioeconomic status. ${ }^{1}$ Effective treatment of $\mathrm{ADHD}$ can help prevent these negative outcomes. ${ }^{4}$

The management of ADHD often requires a multimodal approach. This includes medications, such as psychostimulants (methylphenidate and amphetamine derivatives), non-stimulant medications (eg, atomoxetine) and non-pharmacological interventions (such as behavioural therapies). 
Table 1 Salient differences between diagnostic criteria for ADHD and HKD

\begin{tabular}{|c|c|c|c|c|}
\hline Domain & ICD-10 & DSM-IV & DSM-5 & Notes \\
\hline Symptoms & $\begin{array}{l}\text { A minimum of six symptoms of } \\
\text { hyperactivity out of ten, five } \\
\text { symptoms of inattention out of } \\
\text { nine and one symptom of } \\
\text { impulsivity out of three }\end{array}$ & $\begin{array}{l}\text { Six out of nine symptoms of } \\
\text { inattention and/or hyperactivity/ } \\
\text { impulsivity are required for the } \\
\text { diagnosis }\end{array}$ & $\begin{array}{l}\text { Six out of nine symptoms of inattention } \\
\text { and/or hyperactivity/impulsivity are } \\
\text { required for the diagnosis in children. } \\
\text { Five out of nine symptoms of inattention } \\
\text { and/or hyperactivity/impulsivity are } \\
\text { required for the diagnosis in adults }\end{array}$ & $\begin{array}{l}\text { ICD-10 requires the presence of symptoms } \\
\text { in all the domains of hyperactivity, } \\
\text { impulsivity and inattention. } \\
\text { DSM- } 5 \text { reduces the symptom threshold for } \\
\text { adults and adds examples to facilitate } \\
\text { application across the lifespan }\end{array}$ \\
\hline $\begin{array}{l}\text { Age of } \\
\text { onset }\end{array}$ & $\begin{array}{l}\text { ADHD onset is by definition in } \\
\text { childhood (more specifically, } \\
\text { before the age of } 7 \text { ) }\end{array}$ & $\begin{array}{l}\text { ADHD onset is by definition in } \\
\text { childhood (more specifically, } \\
\text { before the age of } 7 \text { ) }\end{array}$ & $\begin{array}{l}\text { ADHD onset is by definition in childhood } \\
\text { (more specifically, before the age of } 12 \text { ) }\end{array}$ & $\begin{array}{l}\text { DSM- } 5 \text { increases the upper limit of the } \\
\text { age of onset of ADHD symptoms to } 12 \\
\text { years }\end{array}$ \\
\hline Comorbidity & $\begin{array}{l}\text { A comorbid diagnosis with } \\
\text { autism, anxiety and affective } \\
\text { disorders is not allowed }\end{array}$ & $\begin{array}{l}\text { A comorbid diagnosis with autism } \\
\text { is not allowed }\end{array}$ & $\begin{array}{l}\text { A comorbid diagnosis with autism } \\
\text { spectrum disorders is allowed }\end{array}$ & $\begin{array}{l}\text { DSM-5 allows the diagnosis in } \\
\text { comorbidity with autism spectrum } \\
\text { disorders }\end{array}$ \\
\hline Settings & $\begin{array}{l}\text { Inattention and restlessness that } \\
\text { are pervasive across situations at } \\
\text { home and in school/nursery }\end{array}$ & $\begin{array}{l}\text { Symptoms are present in more } \\
\text { than one setting (eg, academic, } \\
\text { social and occupational) and lead } \\
\text { to functional impairment in } \\
\text { various domains }\end{array}$ & $\begin{array}{l}\text { Several inattentive or } \\
\text { hyperactive-impulsive symptoms are } \\
\text { present in two or more settings }\end{array}$ & $\begin{array}{l}\text { DSM-5 strengthens the cross-situational } \\
\text { requirement to 'several' symptoms in each } \\
\text { setting }\end{array}$ \\
\hline Subtypes & None & $\begin{array}{l}\text { Three subtypes: hyperactive/ } \\
\text { impulsive, inattentive, combined }\end{array}$ & $\begin{array}{l}\text { Three ADHD clinical presentations based } \\
\text { on symptom profile: combined, } \\
\text { predominantly inattentive and } \\
\text { predominantly hyperactive/impulsive } \\
\text { presentation }\end{array}$ & $\begin{array}{l}\text { ICD-10 definition of HKD overlaps with the } \\
\text { predominantly combined ADHD subtype } \\
\text { for DSM-IV and combined presentation for } \\
\text { DSM-5. A person can change } \\
\text { 'presentations' during their lifetime }\end{array}$ \\
\hline
\end{tabular}

ADHD, attention deficit/hyperactivity disorder; DSM, Diagnostic and Statistical Manual of Mental Disorders; HKD, hyperkinetic disorders; ICD, International Classification of Diseases.

Indeed, different countries can have licensed different medications and regulations may change between children/adolescents and adults. Extended-release clonidine and extended-release guanfacine have been approved by the FDA for the treatment of ADHD, but not specifically for adults. Other pharmacological options that have been used off-label include modafinil and a number of antidepressants (venlafaxine, bupropion, desipramine, paroxetine, nomifensine, reboxetine and duloxetine). ${ }^{5}$ With regard to the treatment of $\mathrm{ADHD}$ in children and adolescents, a large body of research ${ }^{6}$ shows that ADHD medications are efficacious, at least in the short term, and generally well tolerated for ADHD core symptoms, although recently the quality of available evidence has been questioned. ${ }^{7}$ In terms of non-pharmacological interventions, a series of recent meta-analyses from the European ADHD Guidelines Group $(E A G G)^{8}$ failed to find solid empirical support for their efficacy for ADHD core symptoms. However, the EAGG concluded that nonpharmacological treatments might still be valuable for the treatment of comorbid conditions such as oppositional-defiant and emotional problems. The uncertainty regarding the role of non-pharmacological interventions in the management of $A D H D$ is reflected in the discrepancy in current European guidelines, with the North American practice parameters ${ }^{9}$ suggesting medication as first choice, and the European guidelines recommending a pharmacological treatment only when behavioural interventions are not effective. ${ }^{10-12}$

Given that $A D H D$ in adults has only been recently recognised, evidence on its treatment is overall less developed compared with childhood ADHD. However, the body of empirical research on the treatment of ADHD in adults has been rapidly increasing in the past few years. The aim of this paper is to perform a review of the literature focusing on recent systematic reviews and meta-analyses relevant to the pharmacological and non-pharmacological treatment of adult ADHD (the so-called meta-review), in order to assist clinicians in daily decision-making.

\section{METHODS}

We searched MEDLINE, PubMed, PsycINFO and Cochrane databases from 1 January 2010 to 31 May 2016 for systematic reviews on the pharmacological and non-pharmacological treatment of adults with ADHD. The PubMed search syntax was as follows: (adhd OR ADHD OR attention-deficit/hyperactivity OR attention deficit) AND (meta-analy*
OR metaanaly* OR systematic review* ${ }^{*}$ ). The syntax was adapted for other electronic databases. No language restrictions were applied. As in Huhn et $a{ }^{13}$ full articles were examined by one author (FDC), and two other authors (SC, NA) independently examined a random sample of $20 \%$ of the potentially eligible references. Initial disagreement in the selection of pertinent papers was resolved with discussion by the three authors. We also searched the most recent guidelines/recommendations (last 10 years) on adult ADHD to relate these recommendations to available evidence. References from relevant papers were examined to determine if any relevant studies had been missed during the database searches.

\section{RESULTS}

We initially identified 635 potentially relevant references (see figure 1). After removing non-pertinent references based on title/abstract or full text, we retained a total of 40 pertinent papers (see table 2). We built on these retrieved reviews to address the following clinically relevant questions:

- What is the evidence base for the efficacy of pharmacological treatments of ADHD in adults?

- What is the evidence base for the acceptability and tolerability of pharmacological treatments of ADHD in adults?

- Is there an evidence-based recommended hierarchy in the choice of medications for ADHD in adults?

- What is the evidence base for the efficacy of non-pharmacological treatments of $A D H D$ in adults?

- What is the evidence base for the efficacy of multimodal treatments of ADHD in adults?

- How should adults with ADHD and co-occurring substance abuse be treated?

\section{What is the evidence base for the efficacy of pharmacological treatments of ADHD in adults?}

Overall, pharmacological treatments have been found to be efficacious, at least in the short term, for reducing ADHD symptoms in adults, when compared with placebo (standardised mean difference (SMD) $0.45,95 \% \mathrm{Cl} 0.37$ to 0.52$).{ }^{14}$ Psychostimulants are the most commonly 


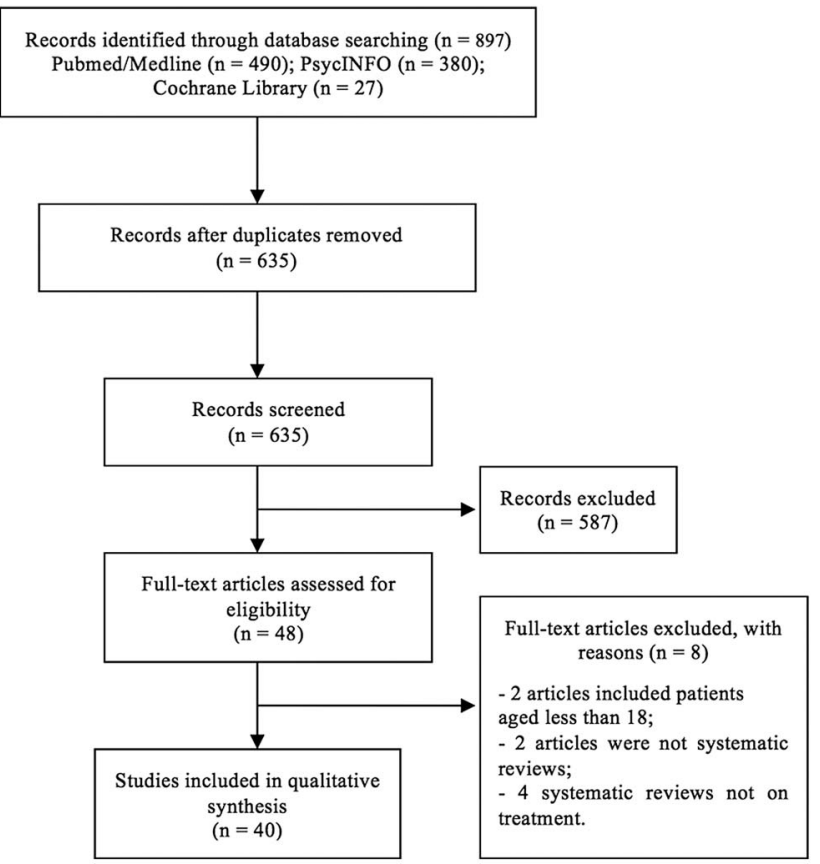

Figure 1 PRISMA flow chart. PRISMA, Preferred Reporting Items for Systematic Reviews and Meta-Analyses.

researched medications for ADHD in children and adolescents, and also in adults.

The British Association of Psychopharmacology (BAP) and the National Institute for Health and Care Excellence (NICE) guidelines, recommend methylphenidate as the first-line pharmacological option in adult ADHD. $^{10}{ }^{12}$ A systematic review by Castells et al ${ }^{15}$ suggests that methylphenidate is significantly more efficacious than placebo in reducing ADHD symptoms, with a moderately large effect size (SMD 0.49, $95 \% \mathrm{Cl} 0.34$ to 0.64 ) in the short term, independent of the type of formulation used, and in a dose-dependent fashion.

With regard to the type of formulation, immediate-release methylphenidate has shown good efficacy on the symptoms of hyperactivity, impulsivity and inattention (SMD $0.54,95 \% \mathrm{Cl} 0.41$ to 0.67). ${ }^{15} \mathrm{~A}$ recent meta-analysis has confirmed the efficacy of methylphenidate also in its sustained-release formulation in adult ADHD, with superiority versus placebo (SMD 0.51, 95\% Cl 0.4 to 0.63 ). ${ }^{16}$ Methylphenidate, regardless of the type of formulation, has also been found to be significantly more efficacious than placebo in reducing executive dysfunctions that are often associated with ADHD (response inhibition: SMD 0.4, 95\% Cl 0.22 to 0.58 ; working memory SMD $0.24,95 \% \mathrm{Cl} 0.0$ to 0.48 ; sustained attention SMD $0.42,95 \% \mathrm{Cl} 0.26$ to 0.59$).{ }^{17}$

Several studies have recently proved the efficacy of other psychostimulants for adult ADHD, with large effect sizes. ${ }^{18-20}$ A Cochrane review found a significant improvement, compared with placebo, in symptom severity for any amphetamine derivative (SMD $-0.73,95 \% \mathrm{Cl}-0.96$ to -0.51 ), dextroamphetamine (SMD $-0.6,95 \% \mathrm{Cl}-1$ to -0.2$)$, mixed amphetamine salts (SMD $-0.73,95 \% \mathrm{Cl}-0.96$ to -0.51 ) and lisdexamfetamine (SMD $-0.8,95 \% \mathrm{Cl}-1.07$ to -0.53$).{ }^{18} \mathrm{~A}$ more recent meta-analysis on lisdexamfetamine confirmed a large effect over placebo on ADHD symptoms (SMD $-0.97,95 \% \mathrm{Cl}-1.15$ to -0.78$){ }^{20}$ Atomoxetine, a non-psychostimulant pharmacological treatment, was found to be more efficacious than placebo in reducing ADHD symptom severity, according to clinician (SMD $0.40,95 \% \mathrm{Cl} 0.48$ to 0.32 ) or patient (SMD 0.33, 95\% Cl 0.43 to 0.23 ) ratings. ${ }^{21}$ Moreover, two studies $^{22} 23$ found a significant improvement in the clinical global impressions of ADHD severity for atomoxetine versus placebo in shortterm (34.8\% vs $22.3 \%)$ and long-term (43.4\% vs $28.0 \%)$ analyses.
Atomoxetine was found to be superior to placebo, ${ }^{16}$ albeit with smaller effect sizes (SMD 0.47, 95\% Cl 0.37 to 0.56 ) than those previously reported for amphetamines, but not smaller than those obtained for the methylphenidate (see above). However, no significant difference between atomoxetine and sustained-release methylphenidate was found in efficacy (SMD $-0.05,95 \% \mathrm{Cl}-0.17$ to 0.07$).{ }^{16}$ The noninferiority of atomoxetine versus methylphenidate, for the reduction of ADHD symptoms in adults, was demonstrated also in a meta-analysis of studies with a direct comparison, which resulted in a non-significant difference in favour of methylphenidate labsolute difference $-0.9 \%$, $95 \% \mathrm{Cl}-9.2 \%$ to $7.5 \%) .{ }^{24}$ Indeed, the effect size for methylphenidate seems to be smaller in adults than that quoted for children and adolescents, while the effect size for the amphetamines is not.

Available systematic reviews found only preliminary evidence (few studies with a low sample size and methodological issues) to support the efficacy of bupoprion, ${ }^{25}$ buspirone, ${ }^{26}$ aripiprazole, ${ }^{27}$ magnesium ${ }^{28}$ and reboxetine ${ }^{29}$ in adults with ADHD.

\section{What is the evidence base for the acceptability and tolerability of pharmacological treatments of ADHD in adults?}

Pharmacological treatments overall, compared with placebo in adults with ADHD, seem to be slightly less well accepted (OR 1.18, 95\% Cl 1.02 to 1.36 ) and less well tolerated (OR 2.29, $95 \% \mathrm{Cl} 1.97$ to 2.66$).{ }^{14}$ Mean adherence rate for all pharmacological treatments in adult ADHD in retrospective naturalistic studies ranged from $52 \%$ to $87 \%{ }^{30}$ In a recent meta-analysis, adults were found to have a higher chance of discontinuation in the long term for all pharmacological treatments of ADHD (79.7\%) compared with children (48.8\%) and adolescents $(72.1 \%){ }^{31}$ Some authors endorse the pro re nata (PRN) regimen (ie, administration of the medicine only as required) in order to improve adherence by improving autonomy of patients, reducing side effects and saving costs. ${ }^{30}$

Compared with placebo, the acceptability of methylphenidate in adults with ADHD did not significantly differ in randomised controlled trials (RCTs) (OR 1.19, 95\% Cl 0.82 to 1.74). ${ }^{32}$ However, the osmoticcontrolled release oral delivery system (OROS) methylphenidate (a sustained-release formulation) can be less acceptable than placebo (OR $1.68,95 \% \mathrm{Cl} 1.25$ to 2.28$){ }^{16}$ The tolerability of methylphenidate, measured as adverse-event induced discontinuation, was found to be significantly worse than placebo (OR $2.68,95 \% \mathrm{Cl} 1.81$ to 3.98$).{ }^{32}$

The retention in treatment in randomised clinical trials did not differ from placebo for any amphetamine derivative (risk ratio (RR) 1.06, 95\% $\mathrm{Cl} 0.96$ to 1.18), dexamphetamine (RR $0.96,95 \% \mathrm{Cl} 0.8$ to 1.14 ) and lisdexamfetamine (RR 0.99,95\% Cl 0.88 to 1.11). ${ }^{18}$ However, mixed amphetamine salts increased the retention in treatment compared with placebo (RR 1.19, 95\% Cl 1.06 to 1.35). The tolerability was lower for any amphetamine derivative versus placebo (RR 3.03, 95\% Cl 1.52 to 6.05), although this estimate is likely to be imprecise as adverse events are not always well reported in clinical studies. ${ }^{18}$

In a meta-analysis on 2665 adults with ADHD, the use of psychostimulants was significantly correlated with a mean increase in resting heart rate of $5.7 \mathrm{bpm}$ and an increased systolic blood pressure of mean $2 \mathrm{~mm} \mathrm{Hg}{ }^{33}$ This meta-analysis, however, has found a low rate of clinically significant cardiovascular events, including hypertension and tachycardia. Nonetheless, another systematic review identified a probable increased risk for transient ischaemic attack and sudden death/ventricular arrhythmia in adult ADHD treated with stimulants, although the magnitude and clinical impact of this increased risk need further clarification. $^{34}$

Other common non-serious adverse events for stimulants include decreased appetite and insomnia, ${ }^{31} 35$ which can often be a cause of discontinuation. ${ }^{30}$ NICE guidelines ${ }^{10}$ recommend to closely monitor 


\begin{tabular}{|c|c|c|c|c|c|c|}
\hline Study & $\begin{array}{l}\text { Type of studies } \\
\text { included }\end{array}$ & Study design & Population & Intervention & Comparison & Primary outcomes \\
\hline Arnold et al ${ }_{1}^{38} 2015$ & Observational studies & Systematic review & Children, adolescents and adults & Any treatment & Any & Long-term outcomes ( $\geq 2$ years) \\
\hline Arnold et al, ${ }^{39} 2015$ & Observational studies & Systematic review & $\begin{array}{l}731668 \text { Children, adolescents and } \\
\text { adults }\end{array}$ & Any treatment & Any & Long-term academic achievement \\
\hline $\begin{array}{l}\text { Asherson et al, } \\
2014\end{array}$ & RCTs & $\begin{array}{l}\text { Pooled analysis of } \\
\text { sponsored trials }\end{array}$ & 1413 Adults & Atomoxetine & Placebo & Symptoms of ADHD \\
\hline $\begin{array}{l}\text { Asherson et al, } \\
2015\end{array}$ & RCTs & $\begin{array}{l}\text { Pooled analysis of } \\
\text { sponsored trials }\end{array}$ & 829 Adults & Atomoxetine & Placebo & Emotional control \\
\hline Bangs et al, ${ }^{37} 2014$ & RCTs & Meta-analysis & $\begin{array}{l}7248 \text { Children, adolescents and } \\
\text { adults }\end{array}$ & Atomoxetine & Placebo & $\begin{array}{l}\text { Suicide-related behaviour or } \\
\text { ideation }\end{array}$ \\
\hline Barkla et al, ${ }^{54} 2015$ & $\begin{array}{l}\text { Animal and human } \\
\text { studies }\end{array}$ & Systematic review & $\begin{array}{l}\text { Adolescents and adults with } \\
\text { substance abuse }\end{array}$ & $\begin{array}{l}\text { Methylphenidate, atomoxetine, dexamphetamine, } \\
\text { lisdexamfetamine }\end{array}$ & Any & $\begin{array}{l}\text { Side effects of combining ADHD } \\
\text { medication with alcohol and drugs } \\
\text { of abuse }\end{array}$ \\
\hline Benson et $a l_{1}^{55} 2015$ & Observational studies & Meta-analysis & $\begin{array}{l}\text { College students with and without } \\
\text { ADHD }\end{array}$ & Stimulant medications & Any & Rates of stimulant misuse \\
\hline Bruce et al, ${ }^{48} 2014$ & $\begin{array}{l}\text { Non-randomised } \\
\text { clinical trials }\end{array}$ & Systematic review & Young drivers & Behavioural interventions & Any & Driving performance \\
\hline Buoli, $^{5} 2016$ & Any & Systematic review & Adults & $\begin{array}{l}\text { Alternative pharmacological treatments (excluding } \\
\text { methylphenidate and atomoxetine) }\end{array}$ & Any & Efficacy and tolerability \\
\hline Bushe et $a l_{,}{ }^{16} 2016$ & RCTs & Meta-analysis & Adults & $\begin{array}{l}\text { Atomoxetine and osmotic-release oral system } \\
\text { methylphenidate }\end{array}$ & Placebo & Efficacy and acceptability \\
\hline $\begin{array}{l}\text { Cairncross and } \\
\text { Miller, }{ }^{43} 2016\end{array}$ & Clinical trials & Meta-analysis & $\begin{array}{l}178 \text { Children, adolescents and } \\
\text { adults }\end{array}$ & Mindfulness-based therapies & Any & Symptoms of ADHD \\
\hline $\begin{array}{l}\text { Caisley and Muller, }{ }_{r}^{30} \\
2012\end{array}$ & Observational studies & Systematic review & Adults & Any pharmacological treatment & Any & Adherence \\
\hline $\begin{array}{l}\text { Camporeale et al, }{ }^{36} \\
2013\end{array}$ & RCTs & $\begin{array}{l}\text { Pooled analysis of } \\
\text { sponsored trials }\end{array}$ & 3314 Adults & Atomoxetine & Placebo & $\begin{array}{l}\text { Sexual and genitourinary adverse } \\
\text { events }\end{array}$ \\
\hline $\begin{array}{l}\text { Castells et al, } \\
2013\end{array}$ & RCTs & Meta-analysis & 2496 Adults & Methylphenidate & Placebo & $\begin{array}{l}\text { All-cause treatment } \\
\text { discontinuation }\end{array}$ \\
\hline $\begin{array}{l}\text { Castells et al, }{ }^{18} \\
2011\end{array}$ & RCTs & Meta-analysis & 1091 Adults & Amphetamines & Any & Efficacy and tolerability \\
\hline $\begin{array}{l}\text { Castells et al, } \\
2011\end{array}$ & RCTs & Meta-analysis & 2045 Adults & Methylphenidate & Placebo & Symptoms of ADHD \\
\hline Chandler, ${ }^{44} 2013$ & Clinical trials & Systematic review & 566 Adolescents and adults & Cognitive-behavioural therapy & Any & Symptoms of ADHD \\
\hline Coghill et al, ${ }^{42} 2013$ & $\begin{array}{l}\text { Observational studies } \\
\text { and clinical trials }\end{array}$ & Systematic review & $\begin{array}{l}\text { Children, adolescents and adults, } \\
\text { healthy and with ADHD }\end{array}$ & Long-acting methylphenidate formulations & $\begin{array}{l}\text { Long-acting methylphenidate } \\
\text { formulations }\end{array}$ & $\begin{array}{l}\text { Comparative efficacy of the } \\
\text { long-acting formulations available }\end{array}$ \\
\hline Coghill et al, ${ }^{35} 2014$ & $\begin{array}{l}\text { Observational studies } \\
\text { and clinical trials }\end{array}$ & Systematic review & Children, adolescents and adults & Lisdexamfetamine & Any & Safety \\
\hline Cunill et al, ${ }^{21} 2013$ & RCTs & Meta-analysis & 3375 Adults & Atomoxetine & Placebo & $\begin{array}{l}\text { All-cause treatment } \\
\text { discontinuation }\end{array}$ \\
\hline Cunill et al, ${ }^{53} 2015$ & RCTs & Meta-analysis & $\begin{array}{l}1271 \text { Children, adolescents and } \\
\text { adults with co-occurring ADHD and } \\
\text { substance use disorder }\end{array}$ & Any pharmacological treatment & Placebo & $\begin{array}{l}\text { Symptoms of ADHD, all-cause } \\
\text { treatment discontinuation, drug } \\
\text { abstinence }\end{array}$ \\
\hline Cunill et al, ${ }^{14} 2016$ & RCTs & Meta-analysis & 9952 Adults & Any pharmacological treatment & Placebo & $\begin{array}{l}\text { All-cause treatment } \\
\text { discontinuation }\end{array}$ \\
\hline Frank et al ${ }_{i}^{31} 2015$ & $\begin{array}{l}\text { Observational studies } \\
\text { and clinical trials }\end{array}$ & Systematic review & Children, adolescents and adults & $\begin{array}{l}\text { Amphetamine, methylphenidate, atomoxetine, } \\
\text { guanfacine, clonidine }\end{array}$ & Any & Adherence and side effects \\
\hline
\end{tabular}


Table 2 Continued

\begin{tabular}{|c|c|c|c|c|c|c|}
\hline Study & $\begin{array}{l}\text { Type of studies } \\
\text { included }\end{array}$ & Study design & Population & Intervention & Comparison & Primary outcomes \\
\hline $\begin{array}{l}\text { Fredriksen et al, } \\
2013\end{array}$ & $\begin{array}{l}\text { Observational studies } \\
\text { and clinical trials }\end{array}$ & Systematic review & Adults & Amphetamine, methylphenidate, atomoxetine & Any & Efficacy and tolerability \\
\hline $\begin{array}{l}\text { Fridman et al, }{ }^{19} \\
2015\end{array}$ & RCTs & Meta-analysis & $\begin{array}{l}6770 \text { Children, adolescents and } \\
\text { adults }\end{array}$ & $\begin{array}{l}\text { Lisdexamfetamine, atomoxetine, osmotic-release } \\
\text { oral system methylphenidate }\end{array}$ & Placebo & Symptoms of ADHD \\
\hline Ganizadeh, ${ }^{27} 2013$ & Clinical trials & Systematic review & Children, adolescents and adults & Aripiprazole & Any & Efficacy and tolerability \\
\hline Ganizadeh, ${ }^{28} 2013$ & Clinical trials & Systematic review & Children, adolescents and adults & Magnesium & Any & Efficacy and tolerability \\
\hline Ganizadeh, ${ }^{29} 2015$ & Clinical trials & Systematic review & Children, adolescents and adults & Reboxetine & Any & Efficacy and tolerability \\
\hline $\begin{array}{l}\text { Gobbo and Louza, } \\
2014\end{array}$ & RCTs & Systematic review & 283 Adults & $\begin{array}{l}\text { Methylphenidate, mixed amphetamine salts, } \\
\text { atomoxetine and lisdexamfetamine }\end{array}$ & Any & Driving performance \\
\hline Jensen et al, ${ }^{46} 2016$ & Clinical trials & Meta-analysis & 85 Adults & Cognitive-behavioural therapy & Treatment as usual & Quality of life and adverse events \\
\hline $\begin{array}{l}\text { Linderkamp and } \\
\text { Lauth, }{ }^{51} 2011\end{array}$ & Clinical trials & Meta-analysis & Adults & $\begin{array}{l}\text { Any pharmacological treatment, } \\
\text { psychotherapeutic therapies }\end{array}$ & Any & Efficacy \\
\hline $\begin{array}{l}\text { Maneeton et al, } \\
2014\end{array}$ & RCTs & Meta-analysis & $\begin{array}{l}146 \text { Children, adolescents and } \\
\text { adults }\end{array}$ & Bupropion & Methylphenidate & $\begin{array}{l}\text { Efficacy, acceptability and } \\
\text { tolerability }\end{array}$ \\
\hline $\begin{array}{l}\text { Maneeton et al, } \\
2014\end{array}$ & RCTs & Meta-analysis & 806 Adults & Lisdexamfetamine & Placebo & $\begin{array}{l}\text { Efficacy, acceptability and } \\
\text { tolerability }\end{array}$ \\
\hline Matsui et al, ${ }^{26} 2016$ & Clinical trials & Systematic review & $\begin{array}{l}499 \text { Children, adolescents and } \\
\text { adults }\end{array}$ & Buspirone & Any & $\begin{array}{l}\text { Efficacy, acceptability and } \\
\text { tolerability }\end{array}$ \\
\hline Mick et al, ${ }^{33} 2012$ & RCTs & Meta-analysis & 2144 Adults & $\begin{array}{l}\text { Methylphenidate, mixed amphetamine salts and } \\
\text { lisdexamfetamine }\end{array}$ & Placebo & Heart rate and blood pressure \\
\hline Shaw et $a l_{,}^{41} 2012$ & $\begin{array}{l}\text { Observational studies } \\
\text { and clinical trials }\end{array}$ & Systematic review & Children, adolescents and adults & $\begin{array}{l}\text { Any pharmacological, non-pharmacological, or } \\
\text { multimodal }\end{array}$ & $\begin{array}{l}\text { Control, proband, placebo, untreated, no } \\
\text { treatment, pretreatment, comparator, } \\
\text { follow-up, normal }\end{array}$ & Long-term outcomes ( $\geq 2$ years) \\
\hline $\begin{array}{l}\text { Tamminga et al, }{ }^{17} \\
2016\end{array}$ & RCTs & Meta-analysis & $\begin{array}{l}1611 \text { Children, adolescents and } \\
\text { adults }\end{array}$ & Methylphenidate & Placebo & Executive functions \\
\hline $\begin{array}{l}\text { Vidal-Estrada et al, }{ }^{45} \\
2012\end{array}$ & Clinical trials & Systematic review & $\begin{array}{l}508 \text { Children, adolescents and } \\
\text { adults }\end{array}$ & $\begin{array}{l}\text { Cognitive-behavioural therapy, metacognitive } \\
\text { therapy, dialectical behaviour therapy, coaching, } \\
\text { cognitive remediation }\end{array}$ & Any & Symptoms of ADHD \\
\hline $\begin{array}{l}\text { Westover and } \\
\text { Halm, }{ }^{34} 2012\end{array}$ & Observational studies & Systematic review & $\begin{array}{l}\text { Children, adolescents and adults } \\
\text { with prescription stimulant use }\end{array}$ & $\begin{array}{l}\text { Methylphenidate, mixed amphetamine salts, } \\
\text { dextroamphetamine }\end{array}$ & Any & Hard cardiovascular outcomes \\
\hline $\begin{array}{l}\text { Weyandt et al, } \\
2014\end{array}$ & Clinical trials & Systematic review & Adolescents and adults & $\begin{array}{l}\text { Lisdexamfetamine, methylphenidate, } \\
\text { amphetamines and mixed-amphetamine salts }\end{array}$ & Any & Efficacy and stimulant misuse \\
\hline
\end{tabular}

ADHD, attention deficit/hyperactivity disorder; RCTs, randomised controlled trials. 
weight, heart rate and blood pressure and to perform a baseline ECG when indicated based on the clinical history.

Bushe et $a^{16}$ found no difference between atomoxetine versus sustained-release methylphenidate in acceptability (SMD 0.85, 95\% Cl 0.61 to 1.2 ), while they found atomoxetine to be less acceptable than placebo (OR 1.33, 95\% Cl 1.09 to 1.63), in accordance with Cunill et $\mathrm{al}^{21}$ (OR $1.39,95 \% \mathrm{Cl} 1.17$ to 1.64). Atomoxetine, compared with placebo, was found to have more sexual and genitourinary side effects (decreased libido, dysuria, urinary hesitation, urine flow decrease, ejaculation and erectile dysfunctions) in adult males with ADHD. ${ }^{36}$ We do not have evidence of significantly greater risk of suicide-related events and suicidal ideation for atomoxetine over placebo in adults with ADHD. $^{37}$

RCTs on medications in adult ADHD are mostly short term and at the present time, the evidence on long-term effects of medications is preliminary with no available pooled effect size. However, improved outcomes for treated than untreated adults with ADHD have been reported. $^{38-41}$

\section{Is there an evidence-based recommended hierarchy in the choice of medications for ADHD in adults?}

According to the NICE, ${ }^{10}$ methylphenidate is the pharmacological treatment with the most solid evidence base and should be considered as the first-line choice in adult ADHD. Other psychostimulants and atomoxetine should be considered as a second choice. Immediate-release or sustained-release formulations should be tailored on the single patient, while PRN regimen can be considered as well.

To date, there are no published evidence-based hierarchies on the efficacy and acceptability of all the most common available pharmacological treatments for ADHD in children as well as in adults. ${ }^{42}$ However, from the reviews mentioned above, the effect sizes on efficacy versus placebo seem higher for amphetamines than for methylphenidate. A recent network meta-analysis ${ }^{16}$ has focused on the comparative efficacy and tolerability of atomoxetine, OROS methylphenidate and placebo. This meta-analysis concluded that atomoxetine did not differ significantly from OROS methylphenidate neither in efficacy nor in acceptability. However, the meta-analysis failed to include other agents available for the treatment of $A D H D$.

\section{What is the evidence base for the efficacy of non-pharmacological treatments of ADHD in adults?}

Addressing behavioural, psychological, educational and occupational needs is recognised to be essential in the treatment of adults with ADHD. ${ }^{10}$ However, while in children and adolescents there is evidence that non-pharmacological treatments are efficacious to address disorders and impairments associated with ADHD (eg, oppositional behaviours and poor parenting via behavioural intervention, and working memory impairment via working memory training), in adults the value of non-pharmacological interventions is less clear. NICE guidelines recommend using pharmacological treatment in adult ADHD as the firstline choice, but they also point out that a psychological treatment should be considered, if it is preferred by the patient. ${ }^{10}$ However, current evidence is mixed and inconclusive. Recent systematic reviews have shown some positive effects on symptoms for the treatment of adult ADHD for mindfulness, ${ }^{43}$ dialectical behaviour therapy ${ }^{44} 45$ and cognitive-behavioural therapy (CBT), ${ }^{44}$ but they were not necessarily based on randomised evidence. Therefore, these approaches still need further research before being possibly integrated in standard practice. In a recent meta-analysis of studies conducted in adults with ADHD, CBT was found efficacious in reducing patient-rated symptoms (SMD -1.0, $95 \% \mathrm{Cl}-1.5$ to -0.5$)$, but not clinician-rated symptoms. ${ }^{46}$ Of note, pharmacological treatments ${ }^{47}$ and behavioural interventions have been found to improve driving performances in adults with ADHD. ${ }^{48}$

\section{What is the evidence base for the efficacy of multimodal treatments of ADHD in adults?}

There is a very weak evidence that multimodal treatment is effective in children and adolescents with $\mathrm{ADHD}{ }^{10}$ In adults with $\mathrm{ADHD}$, two single studies on methylphenidate added on highly structured group CBT versus non-specific clinical management, provided discordant results. ${ }^{49} 50$ However, there is no evidence from systematic reviews, so that this issue needs to be further explored. ${ }^{38} 4151$

\section{How should adults with ADHD and co-occurring substance abuse be treated?}

While there is evidence, from observational prospective studies, showing that children and adolescents with $A D H D$ are at higher risk of long-term substance abuse compared with individuals without ADHD, there is limited evidence on the management of ADHD with co-occurring substance use. ${ }^{52}$ Cunill et al ${ }^{53}$ in a systematic review of 1271 individuals with co-occurring ADHD and substance use disorder, found that pharmacological treatments were efficacious in treating ADHD symptoms (OR 1.93, 95\% Cl 1.4 to 2.66), but were not efficacious on drug abstinence. Another study concluded that there is no evidence of serious side effects in adolescents and adults when ADHD medications are combined with alcohol and drugs of abuse; ${ }^{54}$ however, the limited number of studies reviewed $(\mathrm{N}=20)$, in animals and humans, suggests that caution is needed when interpreting the results of this systematic review. We also note that college students with $\mathrm{ADHD}$ have a rate of misuse of prescription stimulants around $17 \%{ }^{55}{ }^{56}$ Immediate-release stimulants seem to be more likely to be misused than the sustained-release ones. A diagnosis of $A D H D$ is highly correlated to stimulant medication misuse (OR 4.68, 95\% Cl 1.02 to 21.44). ${ }^{55}$ Moreover, in college students with ADHD, a medical history positive for substance use is associated with higher rate of misuse of prescription stimulants. ${ }^{55}$ At present, individuals with co-occurring ADHD and substance abuse should be treated preferably with an integrated approach, including psychoeducation, coaching, CBT and non-stimulant medications or sustained-release stimulants. ${ }^{52}$

We did not find any systematic review focusing on the treatment of adults with ADHD and other comorbidities, which should be further studied in future.

\section{CONCLUSIONS}

Although, initially ADHD was considered as only a disorder of childhood, in the last few years it has been possible to definitely validate ADHD in adulthood. $^{4}$

The diagnosis is clinical, and should be based, when possible, on information gathered from the patient and corroborated by another source. It is reasonable for clinicians in primary care to refer patients to secondary care for a reliable diagnosis and for the treatment management. We summarised our principal findings in table 3. Pharmacological treatment may be considered as the first choice and methylphenidate the first-line option (for the number of studies and participants collected). Amphetamines seem to have higher efficacy from the RCTs, but this result should be taken cautiously as we still do not have a clear hierarchy of medications for efficacy and safety and due to paucity of head-to-head studies, it is premature to provide any firm recommendation. Non-stimulant medications or sustained-release stimulants could be considered for individuals at risk of prescription stimulants misuse. Non-pharmacological treatments can be used as add-on to pharmacological treatment, but while we have evidence of efficacy in children and adolescents, we do not have any evidence of efficacy of multimodal treatments in adults. Subsequently, patients can be followed up in primary care, although in a shared care way, and subjective and objective measurements can be of help at this stage to monitor the clinical condition. In the long term, it is important to weigh the benefits 
Table 3 Principal findings retrieved from six clinically relevant questions

Clinically relevant questions
What is the evidence base for the efficacy of pharmacological

treatments of ADHD in adults?

What is the evidence base for the acceptability and tolerability of pharmacological treatments of ADHD in adults?

Is there an evidence-based recommended hierarchy in the choice of medications for ADHD in adults?

What is the evidence base for the efficacy of non-pharmacological treatments of $A D H D$ in adults?

What is the evidence base for the efficacy of multimodal treatments of ADHD in adults?

How should adults with ADHD and co-occurring substance abuse be treated?
Principal findings (each line reports the findings of individual systematic reviews)

- All pharmacological treatments are more efficacious than placebo ${ }^{14}$

- Methylphenidate is more efficacious than placebo ${ }^{15}$

- Immediate-release and sustained-release methylphenidate are more efficacious than placebo ${ }^{15} 21$

- Methylphenidate is more efficacious than placebo in reducing executive dysfunctions ${ }^{17}$

- Dextroamphetamine, amphetamine salts and lisdexamfetamine are more efficacious than placebo ${ }^{18} 20$

- Atomoxetine is more efficacious than placebo ${ }^{21-23}$

- No difference between atomoxetine and sustained-release methylphenidate was found in efficacy ${ }^{16}$

- Only preliminary results on efficacy are available for bupropion, ${ }^{25}$ buspirone, ${ }^{26}$ aripiprazole, magnesium, ${ }^{28}$ and reboxetine ${ }^{29}$

- All pharmacological treatments are less accepted and tolerated than placebo ${ }^{14}$

- Mean adherence rate for all pharmacological treatments is from $52 \%$ to $87 \%{ }^{30}$

- Higher discontinuation in the longer term in adults than in children ${ }^{31}$

- Methylphenidate is equally acceptable but less tolerable than placebo ${ }^{32}$

- OROS methylphenidate is less acceptable than placebo ${ }^{16}$

- Dexamphetamine and lisdexamfetamine are equally acceptable than placebo ${ }^{18}$

- Mixed amphetamine salts are more acceptable than placebo ${ }^{18}$

- The tolerability is lower for any amphetamine derivative versus placebo ${ }^{18}$

- All psychostimulants can increase heart rate and systolic blood pressure, but have a low rate of significant cardiovascular events, ${ }^{33}$ probably increase the risk for transient ischaemic attack and sudden death/ventricular arrhythmia, ${ }^{34}$ decrease appetite and provoke insomnia ${ }^{31}{ }^{35}$

- Atomoxetine is less acceptable than placebo, ${ }^{16}{ }^{21}$ but equally acceptable as OROS methylphenidate ${ }^{16}$

- Atomoxetine has more sexual and genitourinary side effects than placebo ${ }^{36}$

- Atomoxetine does not have an increased risk of suicidality versus placebo ${ }^{37}$

- To date, there are no published meta-analytically based hierarchies on the efficacy and acceptability of all available ADHD drugs in adults

- Effect sizes on efficacy versus placebo seem higher for amphetamines than for methylphenidate or atomoxetine

- To date, current evidence is mixed and inconclusive

- Preliminary positive results are available for mindfulness, ${ }^{43}$ dialectical behaviour therapy, ${ }^{44}{ }^{45} \mathrm{CBT}^{44} 46$

- Behavioural interventions can improve driving performances ${ }^{48}$

To date, there is no evidence from systematic reviews/meta-analyses on the efficacy of multimodal treatment in adults

- All ADHD pharmacological treatments are efficacious in treating ADHD symptoms in this clinical population, but not drug abstinence ${ }^{53}$

- To date, there is no evidence of serious side effects of all pharmacological treatments if combined with alcohol and drugs of abuse ${ }^{54}$

- High rate of misuse of prescription stimulants (17\%) in college students with $A D H D^{55} 56$

ADHD, attention deficit/hyperactivity disorder; CBT, cognitive-behavioural therapy; OROS, osmotic-controlled release oral delivery system.

of medication against all the possible side effects, to check the risk of non-medical use of prescription stimulants and to reconsider periodically the treatment options.

In terms of evidence base, while current studies support the efficacy and, overall, the good tolerability of psychostimulants and nonpsychostimulants for ADHD core symptoms in the short term, further evidence is needed to understand how available medications rank in terms of efficacy/tolerability, their long-terms effects and the added value of combining pharmacological and non-pharmacological treatments.

\section{Twitter Follow Franco De Crescenzo @Franco De Crescenzo}

Competing interests SC has received grant or research support from the Solent National Health Service (NHS) Trust, UK. He has received honorarium and travel expenses from the Association for Child and Adolescent Mental Health (ACAMH).

Provenance and peer review Not commissioned; externally peer reviewed.

doi:10.1136/eb-2016-102415

Received 13 June 2016; Revised 20 November 2016; Accepted 25 November 2016

\section{REFERENCES}

1. Faraone SV, Asherson P, Banaschewski T, et al. Attention-deficit/hyperactivity disorder. Nat Rev Dis Primers 2015;1:15020.

2. Moffitt TE, Houts R, Asherson P, et al. Is adult ADHD a childhood-onset neurodevelopmental disorder? Evidence from a four-decade longitudinal cohort study. Am J Psychiatry 2015;172:967-77.

3. Seixas M, Weiss M, Muller U. Systematic review of national and international guidelines on attention-deficit hyperactivity disorder. J Psychopharmacol (Oxford) 2012;26:753-65
4. Thapar A, Cooper M. Attention deficit hyperactivity disorder. Lancet 2016;387:1240-50.

5. Buoli M, Serati M, Cahn W. Alternative pharmacological strategies for adult ADHD treatment: a systematic review. Expert Rev Neurother 2016;16:131-44.

6. Taylor E. Uses and misuses of treatments for ADHD. The second Birgit Olsson lecture. Nord J Psychiatry 2014;68:236-42.

7. Storebo $\mathbf{0 J}$, Ramstad E, Krogh HB, et al. Methylphenidate for children and adolescents with attention deficit hyperactivity disorder (ADHD). Cochrane Database Syst Rev 2015;(11):CD009885.

8. Sonuga-Barke EJ, Brandeis D, Cortese $S$, et al. Nonpharmacological interventions for ADHD: systematic review and meta-analyses of randomized controlled trials of dietary and psychological treatments. Am J Psychiatry 2013;170:275-89.

9. Pliszka S. Practice parameter for the assessment and treatment of children and adolescents with attention-deficit/hyperactivity disorder. J Am Acad Child Adolesc Psychiatry 2007:46:894-921.

10. National Institute for Health and Care Excellence (NICE). Attention deficit hyperactivity disorder: diagnosis and management NICE guidelines [CG72]. 2016. https:// http://www.nice.org.uk/guidance/cg72 (accessed 12 Apr 2016).

11. Taylor E, Dopfner M, Sergeant J, et al. European clinical guidelines for hyperkinetic disorder-first upgrade. Eur Child Adolesc Psychiatry 2004;13:17-30.

12. Bolea-Alamanac B, Nutt DJ, Adamou M, et al. Evidence-based guidelines for the pharmacological management of attention deficit hyperactivity disorder: update on recommendations from the British Association for Psychopharmacology. J Psychopharmacol (Oxford) 2014;28:179-203.

13. Huhn M, Tardy M, Spineli LM, et al. Efficacy of pharmacotherapy and psychotherapy for adult psychiatric disorders: a systematic overview of meta-analyses. JAMA psychiatry 2014;71:706-15.

14. Cunill R, Castells $X$, Tobias A, et al. Efficacy, safety and variability in pharmacotherapy for adults with attention deficit hyperactivity disorder: a meta-analysis and meta-regression in over 9000 patients. Psychopharmacology (Berl) 2016;233:187-97.

15. Castells X, Ramos-Quiroga JA, Rigau D, et al. Efficacy of methylphenidate for adults with attention-deficit hyperactivity disorder: a meta-regression analysis. CNS Drugs 2011;25:157-69. 
16. Bushe C, Day K, Reed V, et al. A network meta-analysis of atomoxetine and osmotic release oral system methylphenidate in the treatment of attention-deficit/ hyperactivity disorder in adult patients. J Psychopharmacol (Oxford) 2016;30:444-58

17. Tamminga HG, Reneman L, Huizenga HM, et al. Effects of methylphenidate on executive functioning in attention-deficit/hyperactivity disorder across the lifespan: a meta-regression analysis. Psychol Med 2016;46:1791-807.

18. Castells X, Ramos-Quiroga JA, Bosch R, et al. Amphetamines for Attention Deficit Hyperactivity Disorder (ADHD) in adults. Cochrane Database Syst Rev 2011;(6): CD007813

19. Fridman M, Hodgkins PS, Kahle JS, et al. Predicted effect size of lisdexamfetamine treatment of attention deficit/hyperactivity disorder (ADHD) in European adults: estimates based on indirect analysis using a systematic review and meta-regression analysis. Eur Psychiatry 2015;30:521-7.

20. Maneeton N, Maneeton B, Suttajit S, et al. Exploratory meta-analysis on lisdexamfetamine versus placebo in adult ADHD. Drug Des Devel Ther 2014;8:1685-93.

21. Cunill R, Castells $X$, Tobias $A$, et al. Atomoxetine for attention deficit hyperactivity disorder in the adulthood: a meta-analysis and meta-regression. Pharmacoepidemiol Drug Saf 2013;22:961-9.

22. Asherson $\mathbf{P}$, Bushe $\mathrm{C}$, Saylor K, et al. Efficacy of atomoxetine in adults with attention deficit hyperactivity disorder: an integrated analysis of the complete database of multicenter placebo-controlled trials. J Psychopharmacol (Oxford) 2014;28:837-46.

23. Asherson $\mathbf{P}$, Stes $\mathrm{S}$, Nilsson Markhed M, et al. The effects of atomoxetine on emotional control in adults with ADHD: An integrated analysis of multicenter studies. Eur Psychiatry 2015;30:511-20.

24. Hazell PL, Kohn MR, Dickson $\mathrm{R}$, et al. Core ADHD symptom improvement with atomoxetine versus methylphenidate: a direct comparison meta-analysis. J Atten Disord 2011;15:674-83.

25. Maneeton N, Maneeton B, Intaprasert S, et al. A systematic review of randomized controlled trials of bupropion versus methylphenidate in the treatment of attention-deficit/hyperactivity disorder. Neuropsychiatr Dis Treat 2014;10:1439-49

26. Matsui $\mathbf{Y}$, Matsunaga S, Matsuda $Y$, et al. Azapirones for attention deficit hyperactivity disorder: a systematic review. Pharmacopsychiatry 2016;49:97-106.

27. Ghanizadeh A. Systematic review of clinical trials of aripiprazole for treating attention deficit hyperactivity disorder. Neurosciences (Riyadh) 2013;18:323-9.

28. Ghanizadeh A. A systematic review of magnesium therapy for treating attention deficit hyperactivity disorder. Arch Iran Med 2013;16:412-17.

29. Ghanizadeh A. A systematic review of reboxetine for treating patients with attention deficit hyperactivity disorder. Nord J Psychiatry 2015;69:241-8.

30. Caisley H, Muller U. Adherence to medication in adults with attention defici hyperactivity disorder and pro re nata dosing of psychostimulants: a systematic review. Eur Psychiatry 2012;27:343-9.

31. Frank E, Ozon C, Nair V, et al. Examining why patients with attention-deficit/ hyperactivity disorder lack adherence to medication over the long term: a review and analysis. J Clin Psychiatry 2015;76:e1459-68.

32. Castells $\mathbf{X}$, Cunill $\mathrm{R}$, Capella D. Treatment discontinuation with methylphenidate in adults with attention deficit hyperactivity disorder: a meta-analysis of randomized clinical trials. Eur J Clin Pharmacol 2013;69:347-56.

33. Mick E, McManus DD, Goldberg RJ. Meta-analysis of increased heart rate and blood pressure associated with CNS stimulant treatment of ADHD in adults. Eur Neuropsychopharmacol 2012;23:534-41.

34. Westover AN, Halm EA. Do prescription stimulants increase the risk of adverse cardiovascular events? A systematic review. BMC Cardiovasc Disord 2012;12:41.

35. Coghill DR, Caballero B, Sorooshian $\mathrm{S}$, et al. A systematic review of the safety of lisdexamfetamine dimesylate. CNS Drugs 2014;28:497-511.

36. Camporeale A, Day KA, Ruff D, et al. Profile of sexual and genitourinary treatment-emergent adverse events associated with atomoxetine treatment: a pooled analysis. Drug Saf 2013;36:663-71.
37. Bangs ME, Wietecha LA, Wang $S$, et al. Meta-analysis of suicide-related behavior or ideation in child, adolescent, and adult patients treated with atomoxetine. J Child Adolesc Psychopharmacol 2014;24:426-34.

38. Arnold LE, Hodgkins $\mathrm{P}$, Caci $\mathrm{H}$, et al. Effect of treatment modality on long-term outcomes in attention-deficit/hyperactivity disorder: a systematic review. PLOS ONE 2015; 10:e0116407

39. Arnold LE, Hodgkins P, Kahle J, et al. Long-Term Outcomes of ADHD: Academic Achievement and Performance. J Atten Disord. Published Online First: 12 Jan 2015. pii: 1087054714566076

40. Fredriksen $\mathbf{M}$, Halmoy A, Faraone SV, et al. Long-term efficacy and safety of treatment with stimulants and atomoxetine in adult ADHD: a review of controlled and naturalistic studies. Eur Neuropsychopharmacol 2013;23:508-27.

41. Shaw $\mathbf{M}$, Hodgkins $\mathrm{P}$, Caci $\mathrm{H}$, et al. A systematic review and analysis of long-term outcomes in attention deficit hyperactivity disorder: effects of treatment and non-treatment. BMC Med 2012;10:99.

42. Coghill D, Banaschewski T, Zuddas A, et al. Long-acting methylphenidate formulations in the treatment of attention-deficit/hyperactivity disorder: a systematic review of head-to-head studies. BMC Psychiatry 2013;13:237.

43. Cairncross $\mathbf{M}$, Miller CJ. The effectiveness of mindfulness-based therapies for ADHD: a meta-analytic review. J Atten Disord. Published Online First: 2 Feb 2016. pii: 1087054715625301.

44. Chandler ML. Psychotherapy for adult attention deficit/hyperactivity disorder: a comparison with cognitive behaviour therapy. J Psychiatr Ment Health Nurs 2013;20:814-20.

45. Vidal-Estrada R, Bosch-Munso R, Nogueira-Morais M, et al. Psychological treatment of attention deficit hyperactivity disorder in adults: a systematic review. Actas Esp Psiquiatr 2012:40:147-54.

46. Jensen CM, Amdisen BL, Jorgensen KJ, et al. Cognitive behavioural therapy for ADHD in adults: systematic review and meta-analyses. Atten Defic Hyperact Disord 2016:8:3-11.

47. Gobbo MA, Louza MR. Influence of stimulant and non-stimulant drug treatment on driving performance in patients with attention deficit hyperactivity disorder: a systematic review. Eur Neuropsychopharmacol 2014;24:1425-43.

48. Bruce C, Unsworth C, Tay R. A systematic review of the effectiveness of behavioural interventions for improving driving outcomes in novice drivers with attention deficit hyperactivity disorder (ADHD). Br J Occup Ther 2014;77: 348-57.

49. Philipsen A, Jans T, Graf E, et al. Effects of group psychotherapy, individual counseling, methylphenidate, and placebo in the treatment of adult attention-deficit/ hyperactivity disorder: a randomized clinical trial. JAMA psychiatry 2015; 72:1199-210.

50. Emilsson B, Gudjonsson G, Sigurdsson JF, et al. Cognitive behaviour therapy in medication-treated adults with $\mathrm{ADHD}$ and persistent symptoms: a randomized controlled trial. BMC Psychiatry 2011;11:116.

51. Linderkamp F, Lauth G. Efficacy of pharmacological versus psychotherapeutic therapies in adults with attention deficit/hyperactivity disorder (ADHD): An empirical meta-analysis. Verhaltenstherapie 2011:21:229-38.

52. Matthys F, Stes S, van den Brink W, et al. Guideline for screening, diagnosis and treatment of ADHD in adults with substance use disorders. Int J Ment Health Addict 2014;12:629-47.

53. Cunill R, Castells $X$, Tobias A, et al. Pharmacological treatment of attention deficit hyperactivity disorder with co-morbid drug dependence. J Psychopharmacol (Oxford) 2015;29:15-23.

54. Barkla XM, McArdle PA, Newbury-Birch D. Are there any potentially dangerous pharmacological effects of combining ADHD medication with alcohol and drugs of abuse? A systematic review of the literature. BMC Psychiatry 2015:15:270.

55. Benson K, Flory K, Humphreys KL, et al. Misuse of stimulant medication among college students: a comprehensive review and meta-analysis. Clin Child Fam Psychol Rev 2015;18:50-76

56. Weyandt LL, Oster DR, Marraccini ME, et al. Pharmacological interventions for adolescents and adults with ADHD: stimulant and nonstimulant medications and misuse of prescription stimulants. Psychol Res Behav Manag 2014;7:223-49. 